\title{
Transformations of Contemporary Public Space: Publicity and Visibility in Speaking out on the Internet
}

\author{
Christian Abolo Mbita \\ Department of Television, Advanced School of Mass Communication, Yaounde, Cameroon \\ Email: chris_abolo1@hotmail.fr
}

How to cite this paper: Abolo Mbita, C. (2017). Transformations of Contemporary Public Space: Publicity and Visibility in Speaking out on the Internet. Advances in Journalism and Communication, 5, 205-217. https://doi.org/10.4236/ajc.2017.54012

Received: July 21, 2017

Accepted: September 27, 2017

Published: September 30, 2017

Copyright $\odot 2017$ by author and Scientific Research Publishing Inc. This work is licensed under the Creative Commons Attribution International License (CC BY 4.0).

http://creativecommons.org/licenses/by/4.0/

\begin{abstract}
Since the publishing of Jürgen Habermas' masterpiece where he described the public sphere as an illustration of publicity in the bourgeois milieu of the 18th century, the public space went through substantial changes. This transformation, in the first instance, was due to the fact that laymen speeches have been excluded from it for a long time. The liberation of expression led to a remarkable change i.e., the control of utterance no longer intervenes before but after publication, though this used to guide interventions in the public space. As a result, visibility gained the upper hand on publicity. In other words, selfpresence replaced the filtering by gatekeepers. The Internet and its numerous developments symbolized this tendency.
\end{abstract}

\section{Keywords}

Publicity, Visibility, Internet, Web, Public Space

\section{Introduction}

Debates on "the public space" oppose the prescriptive acceptation to a spatial approach of the notion. Urban sociology developed this spatial definition whereby what is public is what is visible and accessible to everyone. Law is based on this definition when it decides on the divide between public space and private space: what happens on the street is accessible but domestic disputes or other scenes taking place indoors are not (Iacub, 2008). In this respect, the Internet can be regarded as a public space and what is published here shall be subjected to the press laws. In political theory, however, the concept of public space is characterized by the fact that public statements are governed by specific criteria which give them a general interest.

Some statements do not deserve to be brought to the attention of all, while oth- 
ers may be. On the basis of these two definitions, the perimeter of "publicity" can be delimited in theories on the formation of public spirit (Habermas, 1978).

An approximate superimposition characterizes these two definitions in the debate on the traditional media space because, statements made visible by the news media in the light of the first definition, were public, as per the second. If we compared what is stated earlier with what is spoken out on the Internet, some visible words are however not public. The public space was expanded when the web clearly differentiated the notions of visibility and publicity. It was the increase in visibility within societies that made possible the democratization of speech and criticism. Such a fundamental change should be studied carefully as it is a direct consequence of the disappearance of filters on the Internet, whose role was precisely to make visible only what they considered public. However, it is now Internet users who themselves define the tenuous and unstable boundary between the public space and the private space. The Internet has replaced a cleavage by a continuous and undifferentiated stream of public and private statements. With the traditional media space, one still indistinctly perceives the depth of the ongoing transformations. At the moment when exchanges on social networks (web, whatsapp, instagram, tweeter, etc.) stir up passions in almost all countries of the world due to information released by Internet users to others concerning varied subjects, this paper is intended as a contribution to the analysis of the processes of visibility and publicity. It aims at sketching out answers to the following questions: What path follows the posting of information on-line? Does the public nature of this information precede their visibility?

\section{The Construction of the Public Space}

The "restricted public sphere" (Habermas, 1978) emerged in the 18th century and took shape in the following century, thanks to the professionalization of editors, journalists, intellectuals and experts, who were granted restricted access to public speech to report on the activities of public figures, such as politicians, business leaders and other civil society actors. This configuration gives primacy to the right to free expression over any other consideration. It is protected by specific safeguards that only the fight against defamation and respect of privacy can mitigate. It is in this trend that in the name of democracy and the public interest, freedom of expression is strongly encouraged. However, the public sphere gives no room to private statements, in other words, what should not be made public does not exist.

On the fringes of this restricted form of the public sphere, there has been another way of speaking out, due to developments in the popular press and photography, which allows professionals to make public information about ordinary citizens with more or less established reputation. The door of public visibility is therefore open to ordinary citizens ${ }^{1}$. What we call the "paparazzi" finds a swift expansion with the development of press photography and raises serious concerns with regard to its avidity in spot news (Warren \& Brandeis, 1890).

${ }^{1}$ This phenomenon spread rapidly in black Africa since the late 1990s, with the uncontrolled development of the print media and later (2010s) of radio and television. 
Therefore, processes are being shaped to build a normative foundation that can legally protect the privacy of citizens. Since the ordinary citizen's activities do not necessarily fall under the general interest, systems are established to protect his life against a brutal intrusion of the public eye.

It is in this context that legal guidelines are set up to preserve the anonymity, the right to the image and people's privacy.

Nowadays, there is a transformation of sensitivities as concerns ordinary people visibility setting. Paradoxically, tolerance over the use by media of private information has undoubtedly diminished, while at the same moment, voluntary exhibition in the media is steadily increasing. It is becoming more and more difficult for the press to call witnesses, report spot news and photograph ordinary citizens without obtaining their consent and submit to strong rules of anonymization. On the other hand, reality television has allowed the media to create lucrative markets by staging the personal lives of willing ordinary people. This shift reflects the refusal to surrender to the media institution a pre-emptive right over the lives of individuals, the latter preferring to expose their personality themselves, according to the moment and format of their choice. This claim also marks the growing importance of the consent of individuals to control their own image. It is not against the "monstration" as such that their mistrust is directed, but against those who can control it, owing to their position.

Born between the end of the 18th century and the end of the 19th century, these two forms of speaking out have for a long time designed the perimeter of the public space, taking as a pretext information production and dissemination costs to restrict access to specialized agents. But, with the arrival of the Internet, public space is expanding to new forms of speaking out.

Ordinary people have always spoken in the public space. The principle of equality had firstly led Sociologists to designate by the term "secular" (Callon, Lascoumes, \& Barthes, 2001) people whose speaking was barely tolerated by the professionals of information. In fact, for a long time, the media have reserved only a very restricted space to their public on their antenna, especially during their programmes of direct broadcast. The participation of the public has even become a laughing stock in some programmes where they are asked to give the meaning of a word or expression from the face of the answers thus arising. In the last two decades even if the formats set up by the professionals of information and entertainment to receive that secular speaking have multiplied, they have remained well framed and the space dedicated to them is still very limited according to the provisions of global broadcast time. Moreover, the legitimacy that journalists have granted it has always been tinged with a strong distrust and even inside the most "naturalistic" tendencies of reality TV, the expression of this speaking out is always encapsulated in a screenwriting closely controlled by professionals ${ }^{2}$. As a result of their monopoly of access to broadcasting means, in ${ }^{2}$ Whether in the upper-middle class tribulations of the Kardashian family and Rich kids of Beverly Hills or in an European or African style reality shows no abusive language, and no incursion in the domain of strictly private life is permitted. 
fact, professionals, editors, directors, producers and journalists are the people who have reserved for themselves the right to select information which were to be made public. In most countries of the world, governing press freedom introduces demanding rules of publicity defining a prior control of information before their visibility is set. In the media and publishing, the gate-keeper ${ }^{3}$ (Abolo Mbita, 1994) had a leading role in the internal control of the editorial content. The public space was "public" in the sense that information made "visible" to all was subject to a previous selection by professionals obeying to ethical standards. This method of production of public space by the media, hence, jointly ensured the visibility and the publicity of statements.

At the same time, a process of domestication of "speech users" has been accomplished for them to follow conventional forms. The constraints placed on the statements that have access to the public place are particularly strong. Scrutinized by all, monitored by the law and recorded for posterity, the person who ventures to speak out in the public space must move out of the ordinary of the conversation in order not to refer to someone or some respondents, but to differentiated publics. Therefore, he must control his expression well by purging its implicits, and by making sure that his statements could be understood by all regardless of the context in which they have been said. The public speech user must also assume his statements by accepting to give his name, by relying on collective representations in order to target general interest and not their personal interest, in brief, the ordinary speech has complied with the long process of shaping intended for producing agreed and legitimate manners of investing in public space. Only some types of media that we qualify as "alternative" have enabled other forms of speaking to deploy. The latter, that have flourished during the liberalization of airwaves in Europe thirty years ago and that is more often found in some African countries where laws and regulations in the field of communication are still interpreted in many different ways, only have a narrow scope (Cardon \& Granjon, 2010).

Thus, the gap between secular and professionals in the traditional media economy only redoubles the opposition that exists between represented and representatives in the public space, the formers being able to move into the world of the latter only by taking a position of a citizen who agrees, of compassionate witness or victims.

Yet, these modes of public expression radically change when the publicizing operation is no longer conceived as a track of a monitored edge, but as the entrance into a continuous space with very visible zones and others which are much less visible. Then, the secular evolve from this status to the one of amateurs and the expression formats that they put on stage, more numerous and varied and consequently richer, stand as liberated.

${ }^{3}$ I had already developed this notion in Programmation des chaines de television françaises généralistes, logique d'acteurs et médiation, (1994), doctorate thesis, University of Bordeaux III. 


\subsection{Liberation of Secular Forms of Expression}

Ordinary people have always spoken out in the public space. The principle of equality had initially led sociologists to designate by "secular" (Callon, Lascoumes, \& Barthes, 2001), hose persons whose speech was barely tolerated by the professionals of the information. For a long time, the media have reserved very little space for their audiences on the air, especially during direct-expression programmes. The participation of the public has even become a laughing stock in some programmes where they are asked to give the meaning of a word or an expression in the light of the answers arising from it. For the past two decades, even if the formats set up by the information and entertainment professionals to accommodate this secular discourse have multiplied, they have remained well framed and the space devoted to them has remained very limited in terms of overall broadcast time. Moreover, the legitimacy granted to it by journalists has always been tinged with a strong mistrust and even in the most "naturalistic" tendencies of reality television; the expression of this word is always encapsulated in a screenwriting closely controlled by professionals ${ }^{4}$. As a consequence of their monopoly of access to the means of dissemination, the professionals, publishers, directors, producers and journalists are in effect those who reserved for themselves the right to select the information which had to be made public. In most countries of the world, legislation on freedom of the press introduces demanding rules of publicity that define prior control of information before visibility is set. In the media and publishing, the gate-keeper ${ }^{5}$ had a leading role in the internal control of editorial content The public space was "public" in the sense that the information made "visible" to all had been the subject of a prior selection by professionals obeying ethical standards. This way of producing the public space by the media thus jointly ensured the visibility and the publicity of statements.

At the same time, a process of domestication of the "speech users" was carried out so that they followed conventional forms. The constraints imposed on statements that access the public space are particularly strong.

Scrutinized by everyone, monitored by the law and recorded for posterity, the person who ventures into the public space must rise out of the ordinary conversation in order not to address himself to anyone or to a few, but to differentiated audiences. He must therefore control his expression by purging its implicits, making sure that his remarks can be understood by all irrespective of the context in which they were held. The public speech user must also assume his statements by accepting to disclose his identity, rely on a collective representation in order to target general interest and not their brief personal interest, the ordinary speech has complied with the long process of shaping to produce agreed and le-

${ }^{4}$ Whether in the bourgeois tribulations of the Kardashian family and the Rich kids of Beverly Hills, or in the European and African reality shows, there is no discrepancy in language or incursion into the domain of strictly private life.

${ }^{5}$ I had already developed this notion in (1994). Programmation des chaînes de télévision françaises généralistes, logiques d'acteurs et médiation, $\mathrm{PhD}$ thesis, University of Bordeaux III. 
gitimate ways of investing media space.

Only a few types of media that we will call "alternative" have allowed other forms of speaking out to be deployed. The latter, which flourished during the liberation of radio broadcasts in Europe about thirty years ago and which are more often found in certain African countries where the laws and regulations on communication are still variously interpreted, have a low impact (Cardon \& Granjon, 2010).

Thus, the gap between secular and professionals in the traditional media economy only redoubles the opposition between represented and representatives in the political space, the former being able to move into the world of the world of the latter only through taking a position of acquiescent citizen, compassionate witness or victim.

These forms of public expression are radically transformed when the publicising operation is no longer conceived as a track of a supervised edge, but as the entry into a continuous space with highly visible areas, others are much less so. The secular then evolve from this status, to that of amateurs and the formats of expression they put on stage, more numerous and diversified and therefore richer, are found as liberated.

\subsection{When Publishing Precedes Monitoring}

With the disappearance of prior editorial control, a new publishing industry has been established on the web. Based on ultra-liberal principles, this form of publishing has rapidly and firmly defined the principle of open publishing which in the Anglo-Saxon system has been designated "open publishing”. It allows anyone to (Curran \& Couldry, 2003) publish facts in photo, video, written, sound, etc., without any moderation, a priori, nor a posteriori. Alternative media networks apply this extreme openness to such an extent that law breaking speeches are published on a daily basis. Members of these networks regularly feel obliged to amend their principles in order to exercise a posteriori moderation in front of unspeakable comments which may attract the wrath of justice to the networks. However, to ensure that the principle of open publishing is perfectly honoured, the operators of the sites concerned make the articles they have condemned accessible by placing them in isolated headings. In so doing, they leave visible the editorial control operation which must be underlined and recognized as such.

These sites push to the extreme limit one of the cardinal principles of new forms of publication on the Internet, namely, shifting editorial control a priori to a posteriori control, in other words, publish first and filter after constituting the golden rule. Most contributive information production sites such as Wikipedia have taken over this modus operandi or have slightly amended it $^{6}$. In the commentaries and discussion forums of the traditional media, the same principle is observed in order to leave open any publication of the Internet user. More or less liberal moderation approaches are then introduced to allow web users to rectify

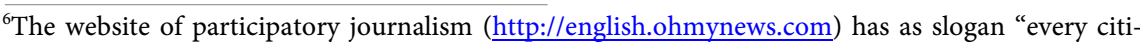
zen is a journalist". 
or delete a posteriori what they consider to be in breach of their editorial charter.

\subsection{Towards a New Industry of Enunciation}

The lifting of gate-keepers controls opens up a new visibility space on the Internet to publishing not subject to prior checking. Under these circumstances, statements may be rendered accessible without being recognized as public. The disappearance of a priori control also lifts the effects of social selection that are at work in the public space when professionals recruit those among the laypersons who demonstrate necessary skills for "public" interest expression. Many critics have shown that (Frazer, 1992) public space is particularly selective from the point of view of social, racial and gender variables. The widening of access to visibility on the Internet has in a way "bartered" from a reduction of the constraints that had founded the forms of public discourse by placing it in the controlling horizon of reason, of self-control, of argumentation and detachment from particular interests. The Internet does not, however, break with the ideals of regulation. They are even sometimes reinforced in certain forms of expert debate. It must nevertheless be acknowledged that the web also opened its nets and encouraged the expression of subjectivities. By suddenly highlighting an expressive diversity that was still invisible, the Internet claims without neither undisguised pride nor censorship that a democratic space of expression can and must be the place of "anyone". Encouragement of the anonymity that the traditional public space prohibits on the Internet highlights its strong tendency towards tolerance of first-person enunciations, peremptory views, what are known as "dissatisfaction outbursts", hazardous statements, etc. The overall industry of enunciation, patiently elaborated to construct legitimate public expression formats, is suddenly called into question.

From the outset, the question that emerges is, if everything becomes visible, how to distinguish between statements of common interest and those that are irrelevant or even more so because of their belonging to the private sphere? The Internet users themselves must proceed, once the statements have been published, to sort within the framework of the respect of the ex post ranking, done by the Internet users according to their position in the structure of the reputations on the web. It is this principle that governs the algorithm of some large portals ${ }^{7}$. This ranking from a certain meritocracy merely transposes the Science Citation Index research evaluation model which prioritises the reputation of researchers according to the number of times they are quoted by other researchers in well-rated journals.

The result is a collective scale of visibility in which legitimate statements are those that appear at the top of the search engines, blog rankings and RSS feeds that aggregate the news. On the other hand, speeches that remain at the bottom

\footnotetext{
${ }^{7}$ The Page Rank that classified search engine responses by the frequency of search terms in the sites is over. It is the social organization of judgments carried out by Internet users that today produces a rank of visibility. It is when a site is ranked well by a lot of sites themselves ranked well that it has a good ranking.
} 
of search engines are barely noticed and do not receive the same public character. It is thus the decision of Internet users to circulate a speech rather than another that indicates the words worthy to be recognized and shared. All those who criticize the Internet and are indignant about finding racist, abusive, defamatory statements do not perceive this characteristic of the web. When considering the web only beneath the prism of the traditional public space, we forget to distinguish accessibility and visibility. Most of the examples that feed these criticisms are certainly accessible; but, for this, one must have sought them, voluntarily with a search engine. They are not visible, not referenced, not cited, not linked, so that they sleep in obscure areas of the web. It can therefore be argued that the Internet is not entirely a public space and that accessible information is not automatically public. There are many pernicious sites that develop ideas of racism, pornography, paedophilia, denial, etc., which attest to the fact that the Internet is the door open to all possible evils.

But it should be borne in mind that this door is often only ajar. These sites, very badly classified in the hierarchy of the web are accessible only to a surfer who seeks them explicitly.

This is why in a country like the United States, in the spirit of the first amendment to the American Constitution, the Internet declines any policy tinged with paternalism that would define for others what they should say see or hear. However, it trusts the self-organized activity of Internet users so that the information that must remain in the depths of the web does not escalate to the rank of visibility.

\section{The Expansion of the Visibility Space}

\subsection{Actors and the Forms of Speaking out}

In order to grasp the current transformations, it is necessary to design a system on the different manners of speaking out in the large space of visibility that the Internet offers. Let's take two types of actors into consideration: the one who speaks and the one whom they talk about. If we postulate then that each actor can be qualified differently on two axes; the one who speaks can be considered firstly as a professional of public speaking or a mere amateur. Then, the one they are talking about can be a well-known personality of the public space (politician, company director, great sportsman, expert, etc.) or a simple ordinary citizen not subject to any particular recognition. This system helps to identify the four possible types of speech and envisage the conflict between the two principles thanks to which we can settle disputes on public speaking. The person who speaks must be protected by the right to the freedom of expression; the one being talked about, by the right to privacy. It is worth recalling here that it is vain to attempt to empower the right to privacy (Solove, 2008) because this right to privacy only makes sense when it is taken as a limitation to the implementation of the other rights, namely the freedom of expression and many others ${ }^{8}$. Therefore, it be-

${ }^{8}$ Domestic violence often occurs in the private sphere; however, they are violation of other rights. 
comes possible to study the way these four types of speaking out have been regulated. It will be noted that the traditional public space, as it appeared with the mass media, has as its pillars a restricted sphere between the personalities and the professionals of the media and politics, then a public sphere located between these professionals and the ordinary citizen; however, the public space created by the web has as main components the space situated between personalities and amateurs (of the media and politics), this sphere where the contributory web unfolds, then the sphere between the above mentioned amateurs and the ordinary citizen, that is presented as a blurred area. How does speaking unfold in this new web public space?

\subsection{Visibility in the Web Public Space}

\subsubsection{The Contributory Web}

Unlike traditional public space, the web enables a simple amateur to have access to visibility by reporting on the activities of public figures. A new form of producers and commentators has surfaced in the public space. A new kind of media sphere has acquired a greater visibility as a result of various events such as attacks, wars, natural disasters, major political jousting etc. Thus, parallel publications by journalists, on the sidelines of the practice of the salaried profession, provision of expertise by specialists in public debate, local counter-information achieved by the inhabitants, news comments by ordinary citizens, mobilization of militants around international issues have become the contents of the "citizen media sphere" within which "citizen journalists" evolve.

Naturally, this expansion meets the expectations of democratization particularly in post-modern societies which still remained very cautious of the criticism targeting a certain tightness of the public space. New actors of the digital public space have been compared to revolutionaries who have undermined the authority of the monarchy with pamphlets (Darnton, 2010), songs and libels (Lemieux, 2000). Studies on this citizen journalism, although very few, show their sociological proximity with the press and publishing profession, as well as their efforts to become more professional. If we take the case of blogs and their authors who often present themselves as citizen journalists, it can be observed that their volume remains modest and that in reality, they comment on current events more than they give new information. Moreover, they mainly specialize in fields of expertise that are treated very little or poorly by the traditional media for the most competent among them, hence interdependent relations with them. But, however small it might be, an expansion of the speaking space certainly contributes to an overall change of practices.

Citizen journalism raises many questions which are all related to its rapid emergence. These interrogations that are already developing in Europe and in the United States (Rebillard, 2007) will soon be addressed to in Africa: should bloggers be given the protections and rights guaranteed to professional journalists? Do they deserve to be granted some privileges such as press card? How can they resist the pressures of public figures wishing to alienate their freedom of 
expression? De facto, authors of blogs do not have the financial and legal protections of a classical media company to face possible suits ${ }^{9}$. All the more since amateurs' statements that animate them, although they pretend to be of public interest, do not always satisfy to the standards of decency, quality, disinterest and truth that were established in the traditional public space. Some even believe that they spearhead the deterioration of the public debate and cultural environment (Keen, 2008). Due to the increase of cases of this type over the years 2000, the question that was raised then was the one of knowing they had to submit the new producers of information to rigorous legal constraints of the "restricted public space" that is press right, respect of privacy, identification of web users etc. Indeed, it was feared that the creation and innovation through the Internet be hampered, if the legal responsibility of web hosts was involved on the same basis as the one of media companies. The French legislator, just to mention him, has been lead to a compromise; the author/editor is solely responsible for his publications, the web host being liable only if he was notified that he was hosting unlawful contents. Despite its fragility and threats constantly looming over it, this compromise somehow preserves the freedom of expression of web users. It should be stated that French parliamentarians regularly propose a systematic identification of web users, but the idea that the liberation of subjectivities on the internet requires some anonymity, in order to have maximum impact still prevails.

\subsubsection{The Web as a Mitigated Area}

Did the intrusion of amateurs in the public space take place only with noble objectives of information production or comment of public events? A vast majority of new entrants in the space of visibility of the web proves the contrary. As it can be observed, their speech matches the shapes of self-presentation; they talk more about themselves, their family (Tisseron, 2003) their tastes, in brief they overexpose their privacy by auto staging, without further reliance on journalists. In this form of expression, we can see ordinary citizens discuss with other ordinary citizens within the framework of an "ethnic" coexistence of a new kind. Individuals who discuss without worrying about who listens to them or sees them outside their close digital circle. The protagonists of this kind of mitigated discussions often imagine that they evolve in a space of limited visibility. Moreover, each web user introduces himself there at the same time as exhibitionist and voyeur, and as it has been suggested in the analysis of relations between the press and the ordinary citizen, he claims simultaneously the protection of his freedom of expression and his rights to privacy. This paradox is a consequence of democratization and massification of the web. According to antagonist conceptions of the internet, two axes can be drawn. The one with those who consider the web as a traditional media and believe that its democratization reflects a simple extension

${ }^{9}$ The owner of a French website platform called Altern in 1999, paid a fine of about $€ 30,000$ for having hosted among his 47,000 sites, the one of an unknown person publishing the pictures of a famous singer's wife, naked, despite the collective support of militants fighting for freedom of expression on the internet. This led to the closing down of the platform. 
of its audience; those people wish to bring new members of the public before well edited pages and framed by advertising spaces. The other with those who hold the web as responsible for a revolution abolishing the frontier between readers, imagine a digital space in which each person would be called to become in turns, an information media and producer of knowledge. Spectators and users are not threatened in their private life. As for editors, they make use of their freedom of expression.

Meanwhile, the extension of the number of users has revealed that they were neither spectators nor potential contributors. The new web users, at the same time younger, less qualified and from a large sociological diversity, join together in proximity micro-frameworks to converse, mock, disseminate facts while adding value to their identity. It is through these micro-speeches, closer to the verbal exchange than the publication of articles that they have mastered the Internet as a social space of a particular type. This web of conversation plays a leading role in the democratization of usages. The new web users take advantage of the internet as agora, that is "very public space" but also as boudoir where their statements are not submitted to the criteria of selection as in the case of traditional public space. But in doing so, they enter into the paradox of public-private life, because they are freely exposed while claiming not to be seen by all.

\section{Conclusion}

Thanks to the divide established between the visible and the public, the Internet has paved the way to many excesses: one can say everything and anything in the model of contributory web and one can exhibit their private life in the mitigated web model. This liberation presents undeniable risks, but as has been seen, the internet does not put everything at the same level of visibility. The worlds of the web are well organized hierarchically and even if those hierarchies may be distorted strategically, they are based on a collective evaluation conducted by web users without any prior consultation. Thanks to the internet, this leads to a renewal of the traditional conception of publicity because, the way web users make, through their links, a hierarchy between an area of high visibility and a mitigated area also constitutes a mode of distinction between public space and private space. This change of category has many consequences.

Firstly, it must be said that the transformation of a clear public/private differentiation into a weak/strong graduation visibility leads from a deliberate and clear choice to a continuous series. Between a high and low visibility, there is an intermediate area of expression whose uncertain status provokes much debate. The distinction between public space and private space incorporated a normative evaluation of the content of statements. However, the distinction between strong/weak visibility is the consequence of a simple digital aggregation that seems totally indifferent to the content of the statement. All the evidence demonstrates that the simple aggregation of numerous and heterogeneous judgments is enough, at least in a first analysis, to produce relevant and quality information. On Wikipedia 
for instance, the quality of an article depends on the number of editors who have intervened on it (Wilkinson \& Huberman, 2007). When it is the subject of focus and control by a great number of people, its reliability is guaranteed. Instead of a substantial judgment on the content of publications, the internet thus substitutes a procedural system that makes the relevance of information depend on the sole enumeration of individual unorganized actions. The evidence is that on Facebook, it is the number of "like" that gives the degree of satisfaction of a "post".

This bold movement constitutes a high-risk bet that consists in entrusting to web users the choice to untie the break of the representation by designating for themselves the information or the topics they consider important. The society is no longer represented by those who had designated themselves to do it. It is no longer projected in the choice, values, professional culture or political orientations of gate-keepers, but pretends to a kind of self-representation that has an umbilical link with the activities of web users. In order to fully identify these systems, we need to analyze the path taken by web users to bring out their statements from the familiar hubbub and install them in the public space.

\section{References}

Abolo Mbita, C. (1994). Programmation des chaînes de télévision françaises généralistes. Logiques d'acteurs et médiation. [Programming of French General-Interest Television Channels. Actor Logics and Mediation.] PhD Thesis, Bordeaux: Université Michel de Montaigne, Bordeaux III.

Callon, M., Lascoumes, P., \& Barthes, Y. (2001). Agir dans un monde incertain: Essai sur la démocratie technique. [Acting in an Uncertain World: Essay on Technical Democracy.] Paris: Le Seuil.

Cardon, D., \& Granjon, F. (2010). Mediactivistes. Paris: Presses de Sciences Po.

Curran, J., \& Couldry, N. (2003). Contesting Media Power. Alternative Media in a Networked World. New York: Rowman \& Littlefield Publishers Inc.

Darnton, R. (2010). Le diable dans un benitier. L'art de la Calomnieen France (pp. 1650-1800). [The Devil in the Holy Water or the Art of Slander in France.] Paris: Gallimard.

Frazer, N. (1992). Rethinking the Public Sphere: A Contribution to the Critic of Actuality Existing Democracy. In C. Calhoun (Ed.), Habermas and the Public Sphere, Cambridge: The MIT Press.

Habermas, J. (1978). L'espace public: Archéologie de la publicité comme dimension constitutive de la société bourgeoise. [Public Space: Archeology of Advertising as a Constitutive Dimension of Bourgeois Society.] Paris: Payot.

Iacub, M. (2008). Par le trou de la serrure. Une histoire de la pudeurpublique. [Through the Keyhole: A History of Public Modesty.] Paris: Fayard.

Keen, D. (2008). Complex Emergencies. Cambridge: Polity Press.

Lemieux, V. (2000). À quoi servent les réseaux sociaux. [ What Are Social Networks for?] Québec: Les Presses de l'Université Laval.

Rebillard, F. (2007). Le Web 2.0 en perspective: Une analyse socio-économique de I'Internet. [ Web 2.0 into Perspective: A Social and Economic Analysis of the Internet.] Paris: L'Harmattan. 
Solove, R. (2008). Understanding Pricacy. Cambridge: Harvard University Press.

Tisseron, S. (2003). L'Intimité surexposée. [Overexposed Intimacy.] Paris: Hachette.

Warren, S., \& Brandeis, L. (1890). The Right to Privacy. Harvard Law Review, 4, 193-220. https://doi.org/10.2307/1321160

Wilkinson, D., \& Huberman, B. (2007). Assessing the Value of Cooperation in Wikipedia. First Monday, 12. https://doi.org/10.5210/fm.v12i4.1763 